\title{
Growth, Elastin Concentration, and Collagen Concentration of Perinatal Rat Lung: Effects of Dexamethasone
}

\author{
JEAN-CLAUDE SCHELLENBERG, GRAHAM C. LIGGINS, AND ALISTAIR W. STEWART \\ Postgraduate School of Obstetrics and Gynaecology [J-C.S., G.C.L.] and Department of Community Health \\ [A.W.S.], The University of Auckland, Auckland, New Zealand
}

\begin{abstract}
The ontogenesis of elastin and collagen accumulation and growth of the lung were studied in Wistar rats from day 18 of gestation until day 30 postnatally. Dexamethasone phosphate $0.1 \mathrm{mg}$ or normal saline solution every $8 \mathrm{~h}$ for three doses was injected into pregnant rats on day 17. The effects of treatment, age, and sex on lung wet weight, lung dry weight, body weight, DNA, protein and desmosine (estimated by radioimmunoassay), and hydroxyproline were determined in the offspring. Dexamethasone inhibited lung growth and, to a lesser extent, body weight gain. While lung wet weight, lung dry weight, and body weight remained significantly reduced until postnatal day 15 , the lung weight/body weight ratio was depressed only until postnatal day 5 . The lung dry weight/ lung wet weight ratio was decreased on day 20 of gestation and at birth. DNA concentration remained slightly but significantly reduced throughout the study period. Desmosine but not hydroxyproline concentration was lower after dexamethasone treatment during the period of rapid postnatal desmosine accumulation (day $10 p<0.05$, day $15 p<0.01$, day $20 p=0.06$ ). (Pediatr Res 21: 603-607, 1987)
\end{abstract}

\section{Abbreviations}

RIA, radioimmunoassay

BSA, bovine serum albumin

Exogenous glucocorticoids accelerate fetal lung maturation in many species including humans (1) and rats (2) and are used to advance lung maturation in the human fetus at risk of preterm delivery. Inhibition of lung growth after prenatal exposure to glucocorticoids has been observed in rabbits $(3)$, rats $(4,5)$, and monkeys (6) and has given rise to concern for the human fetus exposed to such therapy.

One question that arises from these findings in animals is whether "catch-up growth" occurs after the inhibitory effect of glucocorticoids on growth has ceased. Investigations of weight and DNA concentrations have led to the conclusion that catchup growth of the lung occurs after glucocorticoid administration in the pseudoglandular phase in the rabbit (3) and in the canalicular-saccular period in the rat (7). However, to establish whether catch-up growth entails normal structural differentiation, mor-

Received June 26, 1986; accepted January 20, 1987.

Correspondence and reprint requests Dr. J-C. Schellenberg, Postgraduate School of Obstetrics and Gynaecology, National Women's Hospital, Auckland, New Zealand.

Supported by the Medical Research Council of New Zealand and the Lichtenstein-Frank Foundation of the University of Basel, Switzerland. phological (8) or biochemical structural analysis is required. Although elastin and collagen have been used as markers of connective tissue structure of the lung in newborn and adolescent rats $(9-12)$, no data are available on the fetal rat lung. The present study reports the ontogenesis of collagen and elastin accumulation in rat lung between day 18 of gestation and day 30 postpartum and investigates the effects of prenatal glucocorticoid administration on growth and structural development of the rat lung. A radioimmunoassay for the determination of desmosine, a specific cross-link amino acid of elastin (13) is described.

\section{METHODS}

Desmosine for preparing the standards and the antiserum was obtained from Elastin Products, Pacific, MO. Desmosine for preparing the label was provided by Dr. S. J. M. Skinner after purification (14). Collagen type I was provided by Dr. G. Gibson after extraction from rat tail tendon (15). Calf thymus DNA, bovine serum albumin, 1-ethyl-3(3-dimethylamino-propyl)-carbodiimide- $\mathrm{HCl}$, hydroxyproline, and triethylamine were obtained from Sigma Chemical Company, St. Louis, MO. Triethylamine was redistilled over ninhydrin. $\left[{ }^{3} \mathrm{H}\right]$ acetic anhydride was obtained from Amersham International plc, Auckland, New Zealand. Reagents were analytical grade.

Animals and study design. Two series of experiments with differing population structures were performed and analyzed separately. The "fetal rat" series consisted of fetal and newly born rats. The "postnatal rat" series comprised rats of between 5 and 30 days of age.

Fetal Rats. Female virgin outbred Wistar rats from Auckland Medical School were placed with a male at $1700 \mathrm{~h}$ and their vaginas examined for the presence of sperm the next day at 0800 $\mathrm{h}$ (days 0 and 1). On day 17 (pseudoglandular period of lung development) at 0800,1600 , and $2400 \mathrm{~h}$, one group of dams was injected with $0.1 \mathrm{ml}$ saline subcutaneous and another group with $0.1 \mathrm{mg}$ dexamethasone sodium phosphate in $0.1 \mathrm{ml}$ saline subcutaneous (Decadron, Merck, Sharp and Dohme Ltd., Auckland, New Zealand) corresponding to approximately $1 \mathrm{mg}$ dexamethasone sodium phosphate $/ \mathrm{kg}$ body weight/day. A third group of rats was left undisturbed. On days 18 and 20 at $1200 \mathrm{~h}$, the dams were killed by carbon dioxide asphyxia and the fetuses removed from the uterus and stored on ice. Pups delivered spontaneously on day 23 were killed by carbon dioxide asphyxia 3-4 h after delivery. Each fetus and newborn rat was weighed individually and its sex determined (not on day 18). The lungs were dissected free from the hili under a dissecting microscope and individually weighed on a Mettler AC 100 balance (coefficient of accuracy at $10 \mathrm{mg}$ was $0.15 \%$ and at $2 \mathrm{mg}$ was $1.5 \%$ ). The lungs were lyophilized and dried in a vacuum oven at $60^{\circ} \mathrm{C}$ to constant weight. The lungs from each pup in the 18-day-old litters were 
pooled. Lungs of pups from 20-day-old litters were pooled according to the sex of the pup. In each neonatal litter, four males and four females were chosen at random and separated into two male and two female pools of two individuals each.

Postnatal Rats. Breeding and treatment were the same as for the fetal rat group. Only rats that were born on the 23rd day of gestation were used. The litter size was reduced to ten by random removal of pups shortly after birth to eliminate litter size bias due to competition for milk. At 5, 10, 15, 20, and 30 days of age (day of birth = day 1) two animals from each litter (one male and one female if possible) were killed and processed.

Maternal Rats. Postpartum weights of four saline-injected rats were compared with four that were injected with dexamethasone.

Biochemical analysis. Approximately $6 \mathrm{mg}$ of dried pooled tissue was weighed and subjected to papain digestion three times for $24 \mathrm{~h}$ at $65^{\circ} \mathrm{C}$. Aliquots were taken for determination of DNA (16) and of protein (17). Protein values were corrected for protein contained in papain. Approximately $5 \mathrm{mg}$ of tissue was hydrolysed in $1 \mathrm{ml} 6 \mathrm{M} \mathrm{HCl}$ under nitrogen in sealed glass ampoules at $110^{\circ} \mathrm{C}$ for $72 \mathrm{~h}$. The hydrolysates were dried with a vacuum centrifuge and resuspended in water. Aliquots were used for the determination of hydroxyproline (18) and desmosine. Serial dilution curves of hydrolysates from 18 - and 23-day-old fetal rat lungs were linear for hydroxyproline concentration and the blank values were zero. No corrections were made for hydroxyproline contained in elastin. Desmosine was determined by RIA as desmosine tetraacetate after cellulose chromatography (19) followed by acetylation with triethylamine as described below. Standards run in parallel with the samples through chromatography and RIA yielded recoveries of $73 \pm 5 \%$, (mean \pm SEM, $n$ $=2 \times 4$ ).

Desmosine acetate assay. Procedures were similar to those of a previously described assay for isodesmosine (19). Important modifications were as follows.

Antigen. Acetylated desmosine was purified by gradient elution using $100 \mathrm{ml} 0.2 \mathrm{M}$ sodium citrate $\mathrm{pH} 2.4$ and $100 \mathrm{ml} 0.2 \mathrm{M}$ sodium citrate $\mathrm{pH} 4.35$ arranged in series. This yielded three peaks on UV spectrophotometry at $280 \mathrm{~nm}$, the major one of which eluted between $\mathrm{pH} 3.0$ and 3.4 and displayed the typical absorbance spectrum for desmosine and did not react with ninhydrin. Desalting was achieved on a $190 \times 8 \mathrm{~mm}$ Dowex $50 \times 8-200$ column with $250 \mathrm{ml} 0.1 \mathrm{M}$ acetic acid. Desmosine tetraacetate was eluted with $1 \mathrm{M}$ ammonium hydroxide. The molar ratio between desmosine and BSA was 9:1.

Antiserum. Titer was 1:3200.

Label. Specific activity was $10.5 \mathrm{Ci} / \mathrm{M}$ desmosine tetraacetate. Acetylation of Standards and Samples. Triethylamine and acetic anhydride were added to desmosine or to chromatographed hydrolysates suspended in $400 \mu \mathrm{l}$ water in polyethylene tubes. After vortexing, the mixture was left at room temperature for $2 \mathrm{~h}$ and then lyophilized and resuspended in $0.1 \mathrm{M}$ tris $\mathrm{pH}$ 7.2 for RIA. Maximal acetylation was obtained with $10 \mu \mathrm{l}$ triethylamine and $200 \mu \mathrm{l}$ acetic anhydride after $2 \mathrm{~h}$. No difference was found between 1 and $3 \mathrm{~h}$ incubation. Blank values with or without prior chromatography increased zero-binding to a negligible degree. The coefficient of variation for triplicates of desmosine acetylated in the same series was $3 \%(n=8)$. No difference was found between desmosine that had been acetylated once or twice. Correlation between five dilutions of isodesmosine that were acetylated separately and assayed by RIA (19) was linear $\left(r^{2}=0.99\right)$.

Assay. Standards and samples were taken up in $100 \mu \mathrm{l} 0.1 \mathrm{M}$ tris $\mathrm{pH} 7.2$ in glass tubes. Labeled desmosine tetraacetate $(10$ $000 \mathrm{cpm}$ in $90 \mu \mathrm{l} 0.1 \mathrm{M}$ tris $\mathrm{pH} 7.2), 100 \mu \mathrm{l} 0.25 \% \gamma$-globulin, 10 $\mu \mathrm{l}$ lysine acetate $(100 \mu \mathrm{g})$, and $100 \mu \mathrm{l}$ antiserum $(1 / 100)$ in 0.1 $\mathrm{M}$ tris $\mathrm{pH} 7.2$ were added. The mixture was left at $4^{\circ} \mathrm{C}$ for $12-$ $16 \mathrm{~h}$ prior to separation of bound from free ligand with $2.5 \mathrm{ml}$ of $83 \%$ saturated ammonium sulfate.

Specificity of the Assay. Of the 25 acetylated amino acids tested, isodesmosine acetate and lysine acetate cross-reacted most
$(12$ and $0.004 \%)$ and hydroxyproline acetate the least $(<$ $0.0002 \%)$. Cross-reactivity of desmosine and isodesmosine was much less than $0.1 \%$. Chromatographed and nonchromatographed albumin hydrolysates cross-reacted to an unacceptable degree (Fig. 1). Specificity of the assay was satisfactory after saturating nonspecific reactive sites of the antiserum by addition of an excess of lysine acetate $(100 \mu \mathrm{g})$ to each tube, the nonspecific binding in chromatographed neonatal rat lung hydrolysates being $2-6 \%$ (Fig. 1). Cross-reactivity with isodesmosine acetate was reduced from 12 to $7 \%$ by addition of lysine acetate and crossreactivity with desmosine and isodesmosine remained much less than $0.1 \%$. Sensitivity of the assay was about $1.8 \mathrm{ng}$ per tube with a working range between 3.5 and $35 \mathrm{ng}$ using a final dilution of antiserum of $1 / 400$. Recovery of $0-30 \mathrm{ng}$ desmosine acetate added to a constant amount of chromatographed and acetylated fetal rat lung hydrolysate containing about $2 \mathrm{ng}$ desmosine was accurate up to $20 \mathrm{ng}$ desmosine per tube. Serial dilutions of fetal rat lung hydrolysate showed parallelism with the standard curve. Values obtained for desmosine in neonatal rat lung hydrolysate using five different antisera from two sheep were similar considering their respective cross-reactivities with isodesmosine.

Data analysis. Concentrations of desmosine, hydroxyproline, protein, and DNA are expressed per $\mathrm{mg}$ dry weight. The separate effects of treatment, age, and sex on gravimetric and biochemical variables as well as their interactions were studied with a general linear model procedure. Where appropriate, Tukey's multiple comparison test was used. Litter effect was taken into account in the fetal group. The analysis was performed on a 4341 IBM computer using a SAS program (SAS Institute Inc. Cary, NC).

\section{RESULTS}

The decrease in maternal body weight between day 17 and shortly after giving birth was less in the saline group (19 $\pm 7 \mathrm{~g}$; mean $\pm \mathrm{SD})$ than in the dexamethasone-treated group $(41 \pm 4$ g, $p<0.001)$ despite similar weights on day $17(296 \pm 25$ and $292 \pm 24 \mathrm{~g}$ ). Average litter size was similar in the three treatment groups (nine to 16 pups). There were six dead fetuses out of a total of 531 in the fetal group and their occurrence was unrelated to treatment. There was no statistically significant difference between the saline-treated and the control group except for a higher body weight in fetuses of the saline-treated group on day 18 of gestation $(p<0.05)$. Therefore, values for controls and saline-treated animals were pooled for graphical illustration.

Body weight of the offspring, lung wet weight, lung dry weight, and DNA concentration of lungs. Body weight of control animals

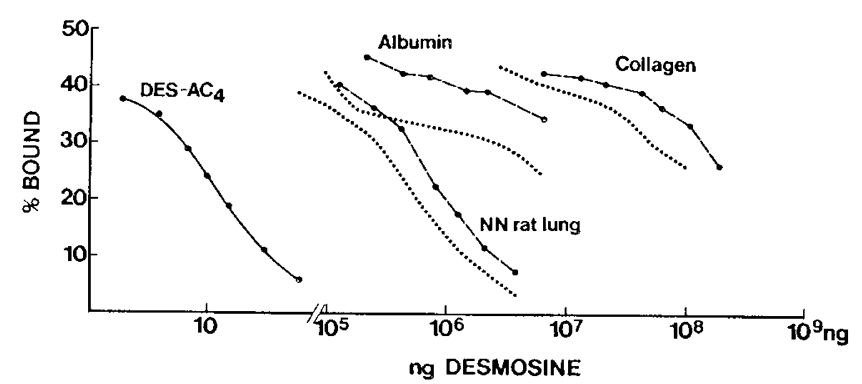

Fig. 1. Displacement of desmosine $\left[{ }^{3} \mathrm{H}\right]$ acetate by desmosine acetate (standard curve, Des- $\mathrm{AC}_{4}$, solid line) and acetylated and chromatographed hydrolysates of neonatal rat lung, BSA, and type I collagen with (broken lines) and without (dotted lines) the addition of excess lysine acetate. To permit the estimation of cross-reactivity in neonatal rat lung between desmosine and other amino acids of noncollagenous or collagenous origin, the weights of neonatal rat lung, albumin, and collagen used in the assay were multiplied by $1,0.6$, and 0.02 , respectively, according to their concentration in neonatal rat lung. Collagen type I was used to estimate cross-reactivity of collagen and albumin to estimate cross-reactivity of noncollagenous protein. 
increased from $0.75 \pm 0.01 \mathrm{~g}(n=61)($ mean \pm SEM) on day 18 of gestation to $6.1 \pm 0.05 \mathrm{~g}(n=56)$ at birth and to $105 \pm 5 \mathrm{~g}(n$ $=6$ ) on postnatal day 30 . Body weight was higher in male than in female fetuses on days 20 and $23(p<0.0001)$ but this trend was minimal postnatally $(p=0.3)$. Lung wet weight of controls increased from $16.5 \pm 0.3 \mathrm{mg}$ on day 18 to $102 \pm 1 \mathrm{mg}$ at birth and to $833 \pm 56 \mathrm{mg}$ on day 30 . Males tended to have higher lung wet weights than females but this was significant only on days $20(p<0.01)$ and $23(p<0.05)$ of gestation. Lung dry weight of controls increased from $2.35 \pm 0.5 \mathrm{mg}$ on day 18 to $18.9 \pm 0.1 \mathrm{mg}$ at birth and to $162 \pm 6 \mathrm{mg}$ on day 30 . Males had higher lung dry weights than females on day 20 of gestation ( $p$ $<0.01)$ and postnatally $(p=0.03)$. DNA concentration in lungs of controls decreased from about $57 \mu \mathrm{g} / \mathrm{mg}$ in fetal and neonatal lung to about $50 \mu \mathrm{g} / \mathrm{mg}$ between days 5 and 20 and to about 42 $\mu \mathrm{g} / \mathrm{mg}$ on day $30(p<0.0001)$. Differences in body weight, lung wet weight, lung dry weight, and DNA concentrations between treatment groups are shown in Figure 2. In postnatal rats (days 5 to 30) DNA concentration was consistently lower in the dexamethasone group than in control and saline-treated rats ( $p$ $<0.01$, all ages together), although the difference was significant only on day $20(p<0.05)$ when each age was analyzed separately.

Dry weight/wet weight ratio of lungs, lung dry weight/body weight ratio, lung wet weight/body weight ratio and protein concentration of lungs. Figure 3 shows mean \pm SEM and statistical differences between treatment groups. On day 20 of gestation, the dry weight/wet weight ratio of lungs was smaller in the dexamethasone group than in the control and saline groups ( $p$ $<0.0001$, corrected for litter effect and wet weight). On day 23 this difference was attenuated but still significant $(p<0.03)$. In dexamethasone-exposed rats, the dry weight/wet weight ratio of lungs was lower in males than in females on day 20 (interaction of sex and treatment, $p<0.02$ ). On day 23 of gestation, both the lung dry weight/body weight ratio and the lung wet weight/body weight ratio were greater in females than in males $(p<0.05)$. Protein concentration was $10 \%$ lower on day 20 than on days 18 and $23(p<0.0001)$. Protein concentration rose nearly $20 \%$ between birth and postnatal day $30(p<0.0001)$.

Desmosine and hydroxyproline concentrations. Figure 4 shows desmosine and hydroxyproline concentrations and statistical differences between treatment groups. In postnatal rats, desmosine concentration was lower in the dexamethasone group on day 10 $(p<0.05)$, day $15(p<0.01)$, and day $20(p<0.06)$. Hydroxy-

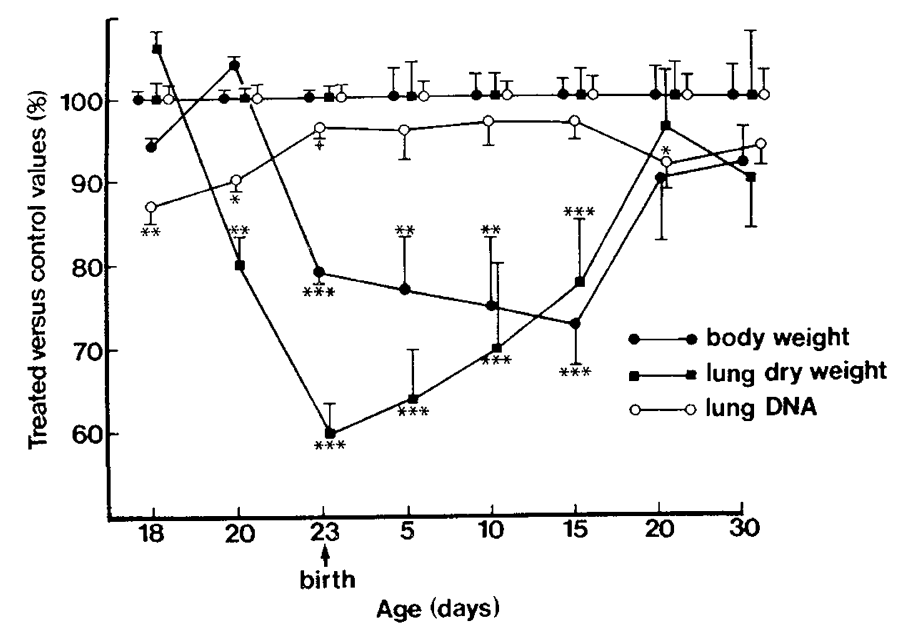

Fig. 2. Body weight, dry weight of lungs, and DNA concentration (per dry weight) of lungs of dexamethasone-treated offspring expressed as percent of control values (pooled values from controls and salinetreated animals $=100 \%) .{ }^{*} p<0.05,{ }^{* *} p<0.01,{ }^{* * *} p<0.001$, where dexamethasone-treated animals differ from controls and saline-treated animals, $\dagger p<0.05$, where dexamethasone-treated animals differ from saline-treated animals only mean \pm SEM.
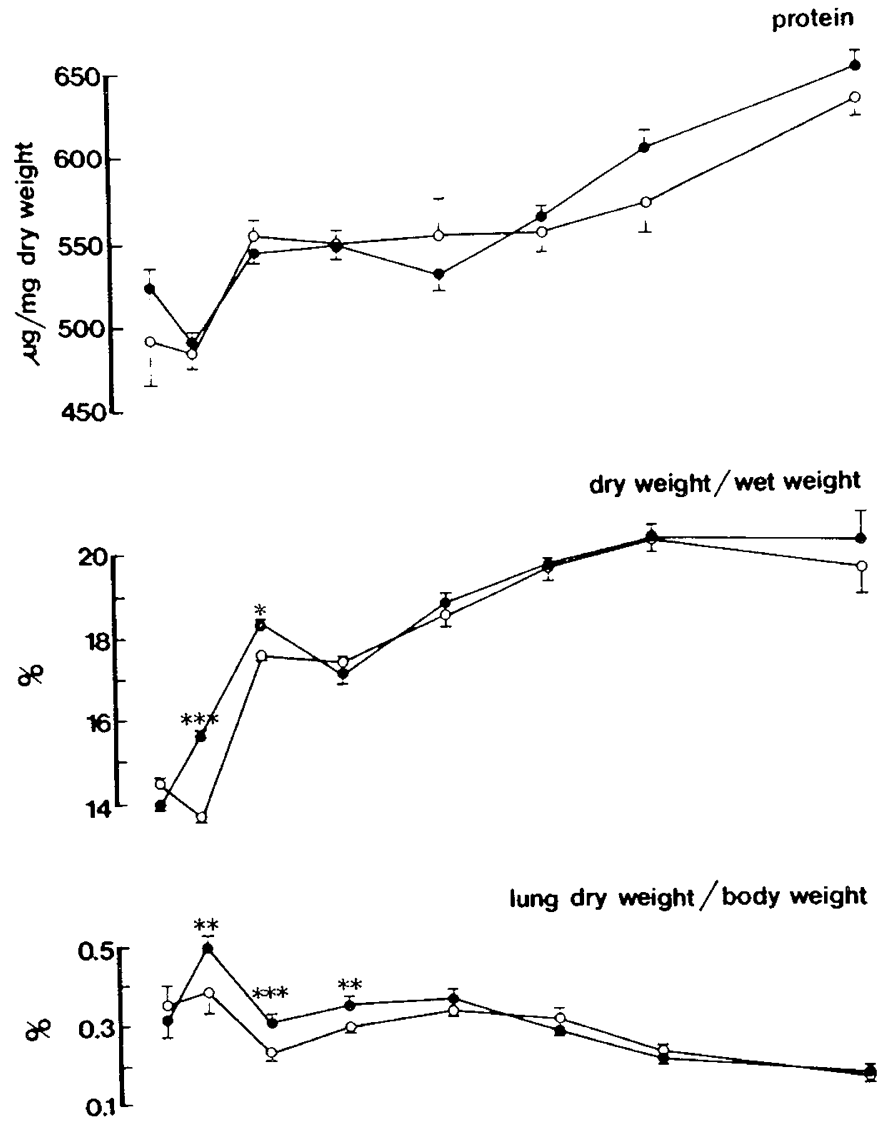

lung wet weight/body weight

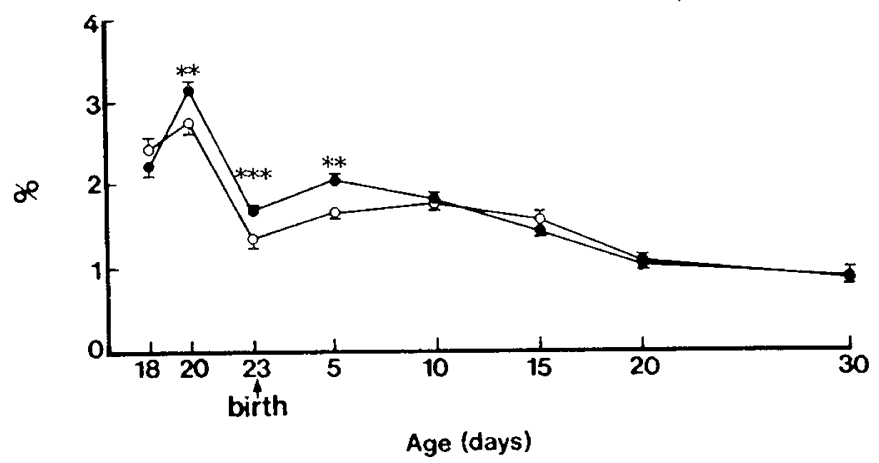

Fig. 3. Protein concentration (per dry weight), lung dry weight/wet weight ratio, lung dry weight/body weight ratio, lung wet weight/body weight ratio in lungs of rats that were exposed to dexamethasone on day 17 of gestation (open circles). Values for controls and saline-treated animals are pooled (closed circles). Statistical symbols as in Figure 2 mean \pm SEM.

proline concentration was not affected by dexamethasone. Lungs of males had slightly higher desmosine concentrations than females on day 20 of gestation $(p=0.05)$.

\section{DISCUSSION}

Normal lung growth. The increase in fetal body weight and lung weight between day 18 of gestation and postnatal day 30 is substantial (5). Major structural transformations of the lungs take place during this period $(20,21)$. Cell density and water content decrease, which is illustrated by the progressive fall in DNA concentration and the increase in the lung dry weight/wet weight ratio. The most likely explanation for the fall in protein concentration on day 20 of gestation is the high contribution to 

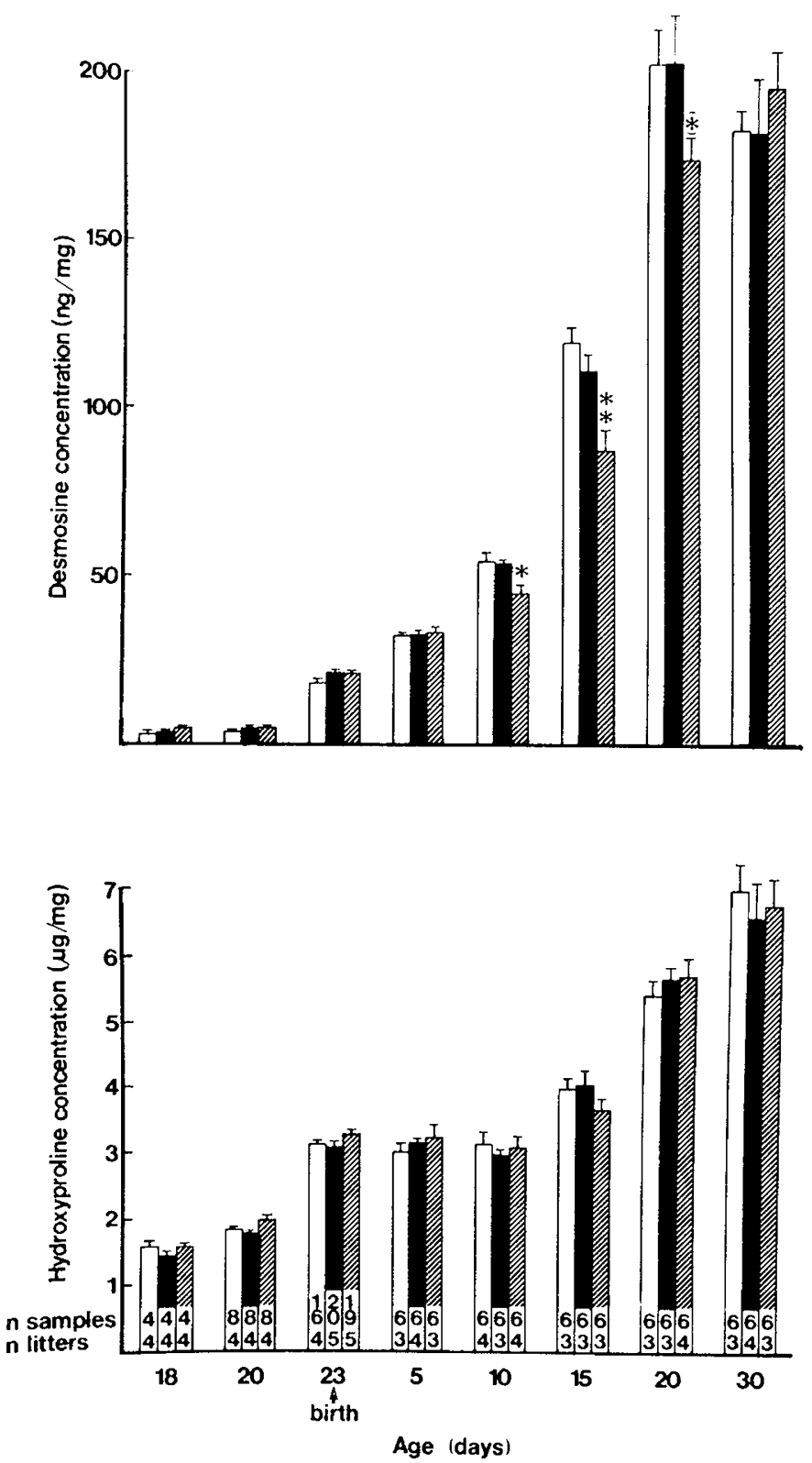

Fig. 4. Desmosine and hydroxyproline concentrations (per dry weight) in fetal rat lung after prenatal exposure to dexamethasone on day 17. Controls (open bars), saline-treated (solid bars), and dexamethasone-treated offspring (hatched bars). ${ }^{*} p<0.05,{ }^{* *} p<0.01,\left({ }^{*}\right) p=0.06$ mean \pm SEM.

lung weight of glycogen (22). The postnatal rise in protein is due, at least in part, to the accumulation of scleroproteins (Fig. 4) (912).

Desmosine and hydroxyproline accumulation in normal lung. The total amount of desmosine per lung increases 55 -fold between day 18 and birth and 90-fold between birth and day 30 . The total amount of collagen per lung increases 14- and 20-fold in the same time periods (see lung weights and Fig. 4). The delay between the rapid phase of alveolar and arterial proliferation [days 3 to $11(20)$ ] and the period of rapid increase in desmosine concentration (day 10 to 20, Fig. 4) corresponds to the interval between the deposition of tropoelastin and the formation of mature cross-links in the extracellular matrix $(11,12,23)$. We report our measurements of desmosine without converting them into elastin equivalents because there is evidence that the desmosine/isodesmosine ratio in elastin of perinatal rat lung changes with age (9). However, assuming that the desmosine concentra- tion in elastin of perinatal rat lung is similar to that in bovine ligamentum nuchae (approximately 1\%), collagen concentration is about 35 times greater than elastin concentration on day 18 of gestation and two to three times greater on postnatal day 30 . This suggests an important role for collagen in perinatal lung structure despite its inconspicuous appearance in peripheral lung tissue (24).

Effect of dexamethasone on weight gain and DNA levels. The earliest observed effect of dexamethasone was a decrease in the DNA concentration on day $18,28 \mathrm{~h}$ after treatment started, followed by a significant reduction in lung weight gain by day 20 . Body weight was affected later (by day 23) and to a lesser degree than lung weight (Fig. 2). The depression in total DNA content in the lungs of dexamethasone-exposed fetuses was considerable and reached a nadir of $60 \%$ at birth and on postnatal day 5 (not shown). The fetal lung appears particularly sensitive to the growth inhibitory effect of exogenous glucocorticoids which is in accord with previous observations $(4,5)$ and is consistent with a high concentration of glucocorticoid receptors in the fetal lung (25). In contrast to lung weight and body weight which remained significantly lower in dexamethasone-treated rats until postnatal day 15 (Fig. 2), the lung dry weight/body weight ratio and the lung wet weight/body weight ratio were significantly depressed only until day 5 (Fig. 3). This suggests that compensatory lung growth of a yet undetermined nature occurs in the growth-retarded, dexamethasone-treated animals. The observed decrease in lung dry weight/lung wet weight ratio (relatively higher water content of the lungs) on days 20 and 23 in dexamethasone-exposed fetuses may be associated with changes in glycosaminoglycans (26).

Effect of dexamethasone on desmosine and hydroxyproline. Hydroxyproline concentration of the lung was not affected by dexamethasone. In contrast, desmosine concentration was significantly lower in dexamethasone-exposed rats during the time period of maximal desmosine accumulation, i.e. on postnatal days 10,15 , and 20 . On day 10 , desmosine content of the lung in dexamethasone-exposed offspring was lowest when compared to controls and saline-treated fetuses (47\%, not shown). It has recently been shown that inhibition of alveolization occurs in the rat when dexamethasone $0.1 \mu \mathrm{g}$ daily is given between postnatal days 4 and $13(27)$. It is improbable that dexamethasone exerted a similar pharmacological effect in our study considering its short plasma half-life [ $5 \mathrm{~h}$ in 35-day-old male Sprague-Dawley rats (28)] and the occurrence of compensatory lung and body weight gain before and during the period of reduced desmosine accumulation. It is likely that the observed effect of dexamethasone on elastin accumulation is caused by events taking place between day 17 and approximately day 19 of gestation. Interference by dexamethasone with the "developmental program" (29) of the rat lung by a yet undefined mechanism is suggested. It has long been recognized that the lung is "constrained by its own developmental program" in compensating for tissue loss or maldevelopment (29). The present data agree with findings in monkeys showing that exposure to glucocorticoids in the pseudoglandular period interferes with normal development of the lung (8). In light of a half-life for elastin in the order of years (12), variations in desmosine concentrations must be caused by changes in the rate of synthesis of tropoelastin or of elastin crosslinks. Whether the reduced levels of desmosine are due to a diminished rate of synthesis per cell or whether they are due to a diminished number of elastin producing cells requires further examination. The finding of persistently lower DNA concentrations in the dexamethasone group (see "Results") gives support to the latter possibility. Our data on DNA concentration are in contrast to two other studies in which full restoration of DNA levels was found. In one study, in the rat, the dose of dexamethasone was less than half the dose we used in the present investigation and it was administered later in gestation (7). In the other study, hydrocortisone was given intrafetally in the rabbit (3). As with lung weight and body weight, desmosine concentrations 
eventually attain normal levels (by day 30, Fig. 4), suggesting that delayed alveolization occurs (27).

Independence of elastin and collagen production. The distinctive time course of collagen and elastin accumulation and the different responses of desmosine and hydroxyproline accumulation to dexamethasone exposure offer further evidence of independence of collagen and elastin metabolism (30). The existence of two or more populations of fibroblasts in the neonatal rat lung, at least one of which produces elastin and another, the lipid-filled interstitial cell, which appears not to be involved in protein synthesis to any great extent, is now well established (31). The present findings suggest that different cell populations are responsible for collagen and elastin production and that glucocorticosteroids selectively affect the cell population that will be involved in elastin synthesis during rapid alveolar multiplication.

\section{REFERENCES}

1. Howie RN, Liggins GC 1982 The New Zealand study of antepartum glucocorticoid treatment. In: Farrell PM (ed) Lung Development: Biological and Clinical Perspectives, Vol 2. Neonatal Respiratory Distress. Academic Press, London, pp 255-265

2. Funkhouser JD, Hughes ER 1980 Fetal lung disaturated phosphatidylcholine. Ostensible increase following exposure to dexamethasone. Biochim Biophys Acta 619:506-514

3. Kotas RV, LeRoy C, Mims C, Hart LK 1974 Reversible inhibition of lung cell number after glucocorticoid injection into fetal rabbits to enhance surfactant appearance. Pediatrics 53:358-361

4. Frank L, Roberts RJ 1979 Effects of low-dose prenatal corticosteroid administration on the premature rat. Biol Neonate $36: 1-9$

5. Mostello DJ, Hamosh M, Hamosh P 1981 Effect of dexamethasone on lipoprotein lipase activity of fetal rat lung. Biol Neonate 40:121-128

6. Johnson JWC, Mitzner W, Beck JC, London WT, Sly DL, Lee PA, Khouzami VA, Cavalieri RL 1981 Long-term effects of betamethasone on fetal development. Am J Obstet Gynecoi 141:1053-1064

7. Frank L, Summerville J, Massaro D 1980 The effect of prenatal dexamethasone treatment on oxygen toxicity in the newborn rat. Pediatrics 65:287-293

8. Bunton TE, Plopper CG 1984 Triamcinolone-induced structural alterations in the development of the lung of the fetal rhesus macacque. Am J Obstet Gynecol 148:203-215

9. Powell JT, Whitney PL 1980 Postnatal development of rat lung. Changes in lung lectin, elastin, acetylcholinesterase and other enzymes. Biochem J $188: 1-8$

10. Nardell EA, Brody JS 1982 Determinants of mechanical properties of rat lung during postnatal development. J Appl Physiol 53:140-148

11. Myers B, Dubick M, Last JA, Rucker RA 1983 Elastin synthesis during perinatal lung development in the rat. Biochim Biophys Acta 761:17-22

12. Dubick MA, Rucker RB, Cross CE, Last JA 1981 Elastin metabolism in rodent lung. Biochim Biophys Acta 672:303-306

13. Foster JA 1982 Elastin structure and biosynthesis: An overview. Methods Enzymol 82:559-570

14. Starcher BC, Galione MJ 1975 A large scale procedure for purification of desmosine and isodesmosine. Prep Biochem 5:455-460

15. Gibson GJ, Shor SL, Grant ME 1982 Effects of matrix macromolecules on chondrocyte expression: synthesis of a low-molecular-weight collagen species by cells cultured within collagen gels. J Cell Biol 93:767-774

16. Burton K 1956 A study of the conditions and mechanism of the diphenylamine reaction for the colorimetric estimation of deoxyribonucleic acid. Biochem J 62:315-323

17. Lowry OH, Rosebrough NJ, Farr AL, Randall RJ 1951 Protein measurement with the Folin phenol reagent. J Biol Chem 193:265-275

18. Stegemann H, Stalder K 1967 Determination of hydroxyproline. Clin Chim Acta 18:267-273

19. Skinner SJM, Schellenberg JC, Liggins GC 1983 The estimation of elastin in fetal tissues by radioimmunoassay of isodesmosine. Connect Tissue Res 11:113-121

20. Meyrick B, Reid L 1982 Pulmonary arterial and alveolar development in normal postnatal rat lung. Am Rev Respir Dis 125:468-473

21. Vidic B, Burri PH 1983 Morphometric analysis of the remodelling of the rat pulmonary epithelium during early postnatal development. Anat Rec 207:317-324

22. Maniscalco WM, Wilson CM, Gross I, Gobran L, Rooney SA, Warshaw JB 1978 Development of glycogen and phospholipid metabolism in fetal and newborn rat lung. Biochim Biophys Acta 530:333-346

23. Partridge SM, Elsden DF, Thomas J 1964 Biosynthesis of the desmosine and isodesmosine cross-bridges in elastin. Biochem $\mathbf{J}$ 93:30c

24. Vaccaro C, Brody JS 1978 Ultrastructure of developing alveoli. I. The role of the interstitial fibroblast. Anat Rec 192:467-479

25. Ballard PL 1977 Glucocorticoid receptors in the lung. Fed Proc 36:2660-2665

26. Skinner SJM, Post M, Torday JS, Stiles AD, Smith BT 1986 Characterization of proteoglycans synthesized by fetal rat lung type II pneumocytes in vitro and the effects of cortisol. Exp Lung Res 11:319-339

27. Massaro D, Teich N, Maxwell S, Massaro GD, Whithney P 1985 Postnatal development of alveoli. Regulation and evidence of a critical period in rats. J Clin Invest 76:1297-1305

28. Varma DR, Mulay S 1980 Anti-inflammatory and ulcerogenic effects and pharmacokinetics of dexamethasone in protein-deficient rats. J Pharmacol Exp Ther 214:179-202

29. Davies P, Reid L 1982 Developmental constraints in compensatory postnatal growth of the lung. J Dev Physiol 4:265-272

30. Myers BA, Dubick MA, Gerreits J Rucker RB, Jackson AC, Reiser KM, Williams SM, Last JA 1983 Protein deficiency: effects on lung mechanics and the accumulation of collagen and elastin in rat lung. J Nutr 113:23082315

31. Brody JS, Kaplan NB 1983 Proliferation of alveolar interstitial cells during postnatal lung growth. Evidence for two distinct populations of pulmonary fibroblasts. Am Rev Respir Dis 127:763-770 